Review Article

\title{
Rotary hood massive break solutions? massive rotator cuff tear solutions?
}

\begin{abstract}
Aim: review the current literature on options of treatment for massive rotator cuff tear

Sources of data: The information was researched on the Pubmed using the following keywords: "massive", "rotator", "cuff", "tear", "treatment". The survey was restricted to articles in english or portuguese, with less than 5 years. After selection 55 articles were used.

Summary of data: Massive Rotator Cuff Tear is an orthopaedic challenge with a technically hard repair and a recurrence rate distinctively higher than the smaller tears rate. Its treatment has a high failure rate, which is influenced by factors such as patient's age, fatty degeneration and muscular retraction. The treatment choice should be based on patient's age, functional demands and symptoms.

Conclusion: There are several options for the treatment of rotator cuff tears. Conservative treatment achieved good results in many patients, leaving many of them assymptomatic and with satisfactory function. The arthroscopic débridement, subacromial decompression and bicips tenotomy have as main objective the symptomatic relief and may be indicated in elderly patients with low functional demands, whose major complaint is pain. Repair should be tried specially in young symptomatic high-demand patients. Both hemiarthroplasty as reverse arthroplasty may be indicated in massive rupture and cuff arthropathy, being reverse arthroplasty the most effective treatment, although the not negligible mid-term complication rate.
\end{abstract}

Keywords: Massive, Rotator, Cuff, Tear, Treatment
Volume 9 Issue $3-2017$

Ana Panzina,' Manuel Gutierres'
'Orthopedics Service, Sao Joao Hospital Center, Portugal
'Faculty of Medicine, University of Porto, Portugal

Correspondence: Ana Teresa Viterbo Panzina, Rua Outeiro do Linho, 93, 4440-6I6 Valongo Portugal, Tel 918124I66, Email ana.panzina@gmail.com

Received: August 23, 2017 | Published: November 16, 2017

\section{Introduction}

Massive Rotator Coil Ruture presents as a complex orthopedic challenge both in pain relief and in restoring shoulder function. ${ }^{1}$ Their repair has a higher rate of recurrence and lower results than minor repair repairs. ${ }^{2,3}$ However, being massive is not synonymous with being irreparable. ${ }^{2}$

The ruptures of the hood are the most common musculotendinous ruptures, ${ }^{4}$ and the prevalence of massive ruptures ranges from $10 \%$ to $40 \%$ and increases with age..$^{2,5-7}$ The first studies to use the term "solid rupture" date from the decades of $70,80 .{ }^{1}$ Since then, several definitions and classifications have been proposed and there is no consensus as to the correct one. Cofield et al. ${ }^{2}$ defined a solid rupture as the rupture with at least $5 \mathrm{~cm}$ in diameter. Already Zumstein et al. ${ }^{8}$ considered that it is massive when detachment occurs of two or more tendons. Taurus et al. ${ }^{2}$ propose an index calculated by multiplying the anteroposterior dimension by the mediolateral rupture.

Ruptures can still be classified as acute or chronic. Only exceptionally acute, ie exclusively traumatic, ruptures occur and usually occur in young patients ${ }^{9}$ or with risk factors such as iatrogenic severe osteopenia due, for example, to prolonged administration of steroids. ${ }^{10}$ Chronics occur almost exclusively in older patients ${ }^{9}$ and, to be considered as such, chronic musculotendinous degenerative changes must be present. ${ }^{10}$ These can be further subclassified as acute chronic ones, when a traumatic event increases a pre-existing rupture. ${ }^{10}$

The classification of the ruptures may also be based on their location: superior posterosuperiores (reaching the tendons of the supraspinatus, infraspinatus and, sometimes, the small round tendon) or anterosuperior (tendons of the supraspinatus and subscapularis associated with instability or rupture of the tendon, ${ }^{9}$ and the massive anterior superior ruptures are less frequent (5 to $20 \%$ ) than the posterior ones (28\%) (2). Most patients (77\%) have rupture on the dominant side. ${ }^{11}$

Finally, Loew and Raiss proposed a classification based on the symptoms and radiological findings that divide the shoulders with massive rupture of the hood in 3 distinct types (Table 1). ${ }^{12}$

Table I Classification of Loew and Raiss

\begin{tabular}{|c|c|c|c|}
\hline & Type I - Arthritic & $\begin{array}{l}\text { Type II - Non } \\
\text { Reactive }\end{array}$ & $\begin{array}{l}\text { Type III - } \\
\text { Necrotic }\end{array}$ \\
\hline Main complaint & Pain in motion & $\begin{array}{l}\text { Capacity reduction } \\
\text { functional with } \\
\text { pseudoparalysis }\end{array}$ & Permanent pain \\
\hline $\begin{array}{l}\text { Amplitude } \\
\text { movement }\end{array}$ & Maintained & Very limited & Extremely limited \\
\hline $\begin{array}{l}\text { Radiological } \\
\text { Findings }\end{array}$ & $\begin{array}{l}\text { Decreased joint } \\
\text { space; } \\
\text { glenoid erosion; } \\
\text { Migration and } \\
\text { subchondral } \\
\text { sclerosis of the } \\
\text { head } \\
\text { humeral; } \\
\text { Osteophytes; } \\
\text { Ossification } \\
\text { of the } \\
\text { coracoacromial } \\
\text { arch. }\end{array}$ & $\begin{array}{l}\text { Upper head } \\
\text { migration } \\
\text { umeral without } \\
\text { changes } \\
\text { osteoarthritis; } \\
\text { Space } \\
\text { maintained }\end{array}$ & $\begin{array}{l}\text { Destruction of the } \\
\text { humeral head and } \\
\text { glenoid; Collapse of } \\
\text { articular surface; } \\
\text { Fractures } \\
\text { subchondral }\end{array}$ \\
\hline Prevalence & $65 \%$ & $24 \%$ & $11 \%$ \\
\hline
\end{tabular}




\section{Biomechanical factors}

The dynamic stability of the glenohumeral joint is based on the synergy of the forces of the deltoid muscle and the rotator cuff in the different planes. ${ }^{2}$ When a massive rupture occurs these coupled forces are modified leading to instability and loss of functions, one of the most important changes being the upper humeral head migration. ${ }^{6,9,13}$ Loehr stated that a single tendon injury does not influence the movement pattern, whereas lesions of 2 or more actually cause joint instability. ${ }^{14}$

Still in an introductory context, it makes sense to perceive and define the various entities that may be related to and / or to be a consequence of the Mass Rotator Coverage Rupture.

\section{Muscle degeneration and fat infiltration}

Loss of tendon insertion in the bone alters physiology, structure, and muscle function. This results in atrophy, and, consequently, muscular retraction, progressive fibrosis and increased adipose content. Several morphological studies report intrafascicular, extrafascicular adipose accumulation and in intratendinous sites, and the origin of the adipocytes is not well defined. They also reveal that adipose infiltration may appear as early as 6 weeks after rupture ${ }^{5}$ and that the degree of muscular degeneration and fat infiltration increases with its size. ${ }^{4}$ Goutallier's Staging is based on the results evidenced by $\mathrm{CT}$ and divides fat infiltration into 5 stages (Table 2). ${ }^{5}$

\section{Table 2 Staging of Goutallier}

\begin{tabular}{ll}
\hline Stadium $\mathbf{0}$ & Normal muscle (without adipose deposits) \\
\hline stadium I & Some fat deposit \\
stadium II & More muscle than adipose tissue \\
stadium III & Same amount of muscle and adipose tissue \\
stage IV & More adipose tissue than muscle \\
\hline
\end{tabular}

Fat infiltration gains importance when clinical studies find that it is associated with a worse prognosis and higher postoperative failure rates. ${ }^{5,15}$ The degree of fatty infiltration of the supraspinatus and infraspinatus seems to be related to a worse prognosis. ${ }^{4,16,17}$ The degree of adipose infiltration in MRI is a strong predictive factor for recurrence of postoperative rupture..$^{9}$

\section{Arthropathy of the rotator hood}

This term was first used by Neer. ${ }^{18}$ It is described as the presence of a massive rupture of the coifera associated with superior migration of the humeral head, reduction of the acromioumeral distance, erosion of the proximal humerus tuberosities ("femorisation") and acetabulization of the acromium..$^{2,19}$

The typical patient is a female of 70 years of age or older, with a history of progressive pain and shoulder movements limited by stiffness. Nocturnal pain is common and Neer et al report an average of 9.8 years of pain history, with many patients already receiving corticosteroid injections for symptomatic relief. An important aspect is that, unlike the isolated coifa rupture, patients with cochlear arthropathy will have loss of active and passive range of motion..$^{18,20}$

\section{Pseudoparalysis}

Pseudoparalysis is defined as an "inability to actively lift the arm in the presence of a free passive range of motion and in the absence of neurological injury" and is caused by upper humeral head migration. ${ }^{18}$ May affect anterior elevation or external rotation. ${ }^{10}$

\section{Suprascapular nerve neuropathy}

Suprascapular nerve neuropathy is considered a rare condition, but is more common in patients with massive rupture. ${ }^{4}$ It is characterized by the presence of pain and muscle weakness. ${ }^{2}$ Boykin et al. reported changes in EMG consistent with this entity in $42 \%$ of patients with massive rupture. ${ }^{21}$ Berhouet et al. reaffirm the rarity of this Finding. ${ }^{22}$

\section{Diagnosis}

The presentation of the massive rotation of the rotators' hood is inconsistent. The pain experienced has variable degrees ${ }^{9}$ and some patients do not report any trauma while others report a traumatic event and a loss of acute function with or without previous symptoms. However, we can say that typical patients are elderly with a history of progressive pain and limitation of shoulder movements associated with stiffness. ${ }^{18}$ The loss of amplitude is, as a rule, more marked in the abduction movement. ${ }^{10}$

During inspection, there are certain signs that can be visualized as peri-scapular atrophy in the supra and infraspinatus fossa, deltoid atrophy, and Popeye deformity present when there is rupture of the proximal tendon of the biceps. ${ }^{9}$

The present muscle deficit is also variable according to the muscle involved in the rupture. When rupture of the supraspinatus occurs, there is weakness during abduction; the infraspinatus rupture causes changes in the external rotation and when there is rupture of the subscapular, then the weakness appears during the internal rotation. ${ }^{20}$ Thus, in the physical examination of the posterior superior ruptures we can observe reduction in abduction, anterior flexion and active external rotation, the latter being proved by a positive external rotation lag signal. We can also find a positive hornblower signal. ${ }^{2}$ Already when we examine an anterosuperior rupture, there are certain signs that are typically positive because of subscapular involvement, such as the belly-press test, Gerber's withdrawal or test, and the bear hug test.

Imaging studies play a key role in both diagnosis and treatment selection, with the most commonly used imaging tests being Ultrasound and Magnetic Resonance Imaging. ${ }^{2}$ Magnetic resonance imaging has a sensitivity of about $100 \%$ in the diagnosis of coifera ruptures, allowing an accurate estimation of the size and patterns of complex ruptures, retraction, fat infiltration and involvement of the biceps tendon (Figure 1). ${ }^{2}$ Ultrasound has the great advantage of being a dynamic examination that allows evaluation of the shoulder during provocative maneuvers. In addition, it is a low-cost, noninvasive exam. ${ }^{9}$ However, it has the disadvantage of having operatordependent sensitivity and specificity and of not penetrating the bone, being a poor method in the evaluation of large ruptures in which the tendons are retracted medially to the lateral edge of the acromion. ${ }^{9}$ Computed tomography helps surgical planning when there are erosive glenoid abnormalities, especially if procedures such as glenoid osteotomy are being considered. ${ }^{20}$ It is also an asset in the evaluation of the competence of the coracoacromial arch. ${ }^{2}$ The use of the Chest X-ray allowed the creation of the Hamada Radiological Classification in 1990, consisting of 5 stages that reflect the temporal evolution of rupture and a successive progression of arthropathy (Table 3). ${ }^{16}$

Table 3 Hamada Radiological Classification

\begin{tabular}{|c|c|}
\hline Stadium I & Acromioumeral interval $>6 \mathrm{~mm}$ \\
\hline Stadium 2 & Acromioumeral interval $<5 \mathrm{~mm}$ \\
\hline Stadium 3 & $\begin{array}{l}\text { Acromioumeral interval }<5 \mathrm{~mm} \text { and acetabulization of the } \\
\text { coracoacromial arch }\end{array}$ \\
\hline Stadium 4 & Narrowed glenohumeral joint \\
\hline Stadium $4 \mathrm{a}$ & Without acetabulization \\
\hline Stadium $4 b$ & With acetabulization \\
\hline Stadium 5 & Collapse of the humeral head (due to osteonecrosis) \\
\hline
\end{tabular}




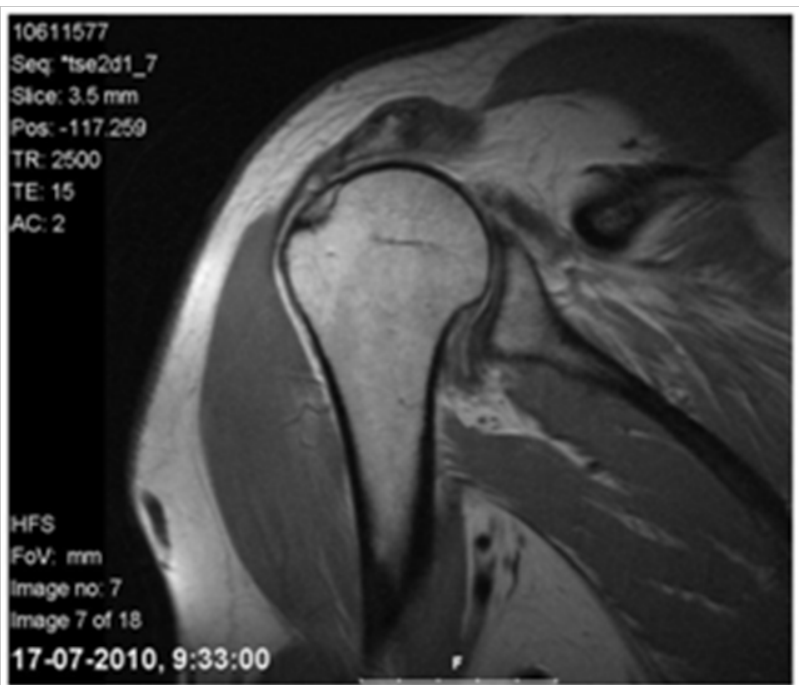

Figure I Magnetic resonance imaging of a 52-year-old man's right shoulder reveals a massive rupture of the rotator cuff with superior humeral head migration, tendon retraction, and muscle atrophy/steatosis.

\section{Treatment}

The massive rotations of the rotator cuff have an unfavorable treatment history since the repair is technically difficult and the rate of recurrence is distinctly greater than that associated with small breaks. ${ }^{2,17}$ The choice of treatment alone is often more complicated than its execution. By aggravating this difficulty, during the course of treatment it is possible for the patient to change his mind, as the symptoms may become unbearable and the functional requirements can go from low to high (or vice versa). Furthermore, an eventual reparable rupture may, in a short time, become irreparable. ${ }^{10}$

The massive breakdown approach is quite challenging, with bankruptcy rates ranging from $20 \%$ to $90 \%-94 \%, 5,23,24$ depending on several factors such as patient age, fat degeneration and atrophy and muscle retraction. The overall outcome and healing capacity are inversely correlated with the size and retraction of the rupture. ${ }^{9,17,23}$ In addition, the time factor is also preponderant. ${ }^{22}$ Petersen et $a l .{ }^{25}$ followed 42 patients with painful massive traumatic rupture and found that the results of surgical repair of the traumatic coil fractures associated with weakness are better when repair occurs at the maximum 4 months after injury.

Another important point in regards to treatment is the awareness that "massive breakdowns" are not synonymous with "irreparable breakdowns"! There are a number of signs that confer irreparable status, such as static upper humeral head migration, reduced or nonexistent acromiomeric interval, and a fat infiltration of $\geq 50 \%$ of the rotator cuff musculature. ${ }^{26}$ There are other findings indicative of irreparability such as pseudoparalysis of anterior elevation and the fact that a rupture is anterosuperior. ${ }^{10}$

When the ruptures are in fact irreparable there are two possible options: palliative treatments such as tenodesis or debridement or salvage procedures such as tendon transfer or reverse arthroplasty (Figure 2). ${ }^{26,27}$

\section{Conservative treatment}

Conservative treatment should include active modification, oral analgesics, physiotherapy, and intra-articular injections. ${ }^{18}$

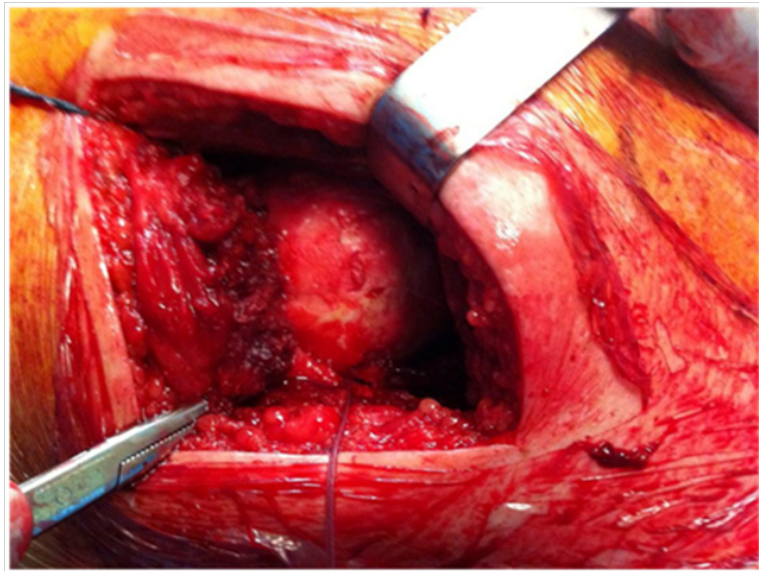

Figure 2 Irrecoverable solid ridge with humeral head completely exposed.

Some authors argue that it will be preferable to treat massive ruptures conservatively since their surgical repair is followed by a high rate of recurrence. ${ }^{2}$ However, the major obstacle to this approach is the lack of evidence that conservative treatment alters the natural course of disease history. ${ }^{10}$ Thus, it should not be used in repairable breaks of patients with high functional requirements and should be reserved for patients without significant pain..,10 Conservative treatment has shown inconsistent and disappointing long-term results, ${ }^{27}$ and has been particularly disappointing in patients with symptoms for more than 6 months, a fact recognized by Bokor et al. ${ }^{12,9}$ The conservative treatment of stiffness is almost always a success, often resulting in pain relief and function restoration. ${ }^{10}$ Zing et al studied the mid-term results of the conservative treatment of 19 patients with massive hood rupture. Patients maintained good shoulder function and preserved active range of motion. However, fatty infiltration and glenohumeral osteoarthrosis progressed, leading inevitably to joint degeneration. ${ }^{10,28}$ Thus, the use of conservative treatment has to be weighed against patients due to the risk of rotator cuff arthropathy and irreversible fat infiltration. $^{2}$

\section{Previous deltoid re-education}

Re-education of the deltoid as a rehabilitation method is validated by recent biomechanical studies that challenged the traditional deltoid view as a humeral head lifts. Gagey et al. concluded that one of the functions of the muscle is to prevent the superior migration of the humeral head and the consequent compression against the glenoid in the presence of a massive rupture. This method of rehabilitation is more commonly used in the elderly with multiple comorbidities that contraindicate surgery. Levy et al studied 17 patients in whom this method was associated with analgesia. In $90 \%$ of patients, the stabilizing effect achieved by deltoid recruitment (anterior) was sufficient to improve functional abilities and decrease pain..$^{29}$

\section{Surgical treatment}

Debridement and Subacromial Decompression.

The main objective of debridement is to remove the sources of pain, which can be performed either open or arthroscopic. ${ }^{9}$ In both approaches there is concern to release the coracoacromial ligament, since it is an important obstacle to anterosuperior sliding of the humeral head. ${ }^{10,20}$ Debridement is indicated In elderly patients with low functional requirements, ${ }^{9,20}$ whose main complaint is pain but with good preservation of the active movement and transverse and coronal forces of intact glenohumeral joint. ${ }^{2}$ It is even indicated in patients unable to undergo long postoperative recovery. ${ }^{30}$ 
The results for this procedure are disparate and it is well established that subacromial debridement has worse results in massive ruptures than in smaller ruptures. ${ }^{10}$ Compared with other surgical options, studies show inferiority of debridement. In a randomized study of massive but reparable ruptures, debridement had less clinical success and more joint degeneration than tendon repair. In addition, there is no evidence that debridement is more effective than isolated bicipital tenotomy. ${ }^{10}$ Patients submitted only to arthroscopic debridement have a less marked improvement in functional capacities than those submitted to partial arthroscopic repair. ${ }^{30}$ Rockwood et al reported 44 cases (88\%) out of 50 in which decreased pain and improved function and strength occurred after debridement and decompression. Already Gartsman et al. registered modest improvements in pain and function after debridement and open decompression, but found a decrease in strength. Zjivac et al. ${ }^{2}$ also found deterioration of strength and function over time after arthroscopic debridement. Liem et al. ${ }^{31}$ retrospectively studied 31 patients, mean age of 71 years, who underwent debridement bicipital tenotomy and coracoacromial arch maintenance. After an average of 47 months, the ASES score improved significantly from 24.0 to 68.9 and pain scores decreased from 7.8 to 2.0.

Despite the existence of some disappointing results, there are certain undeniable advantages of arthroscopic subacromial debridement and decompression: the rehabilitation program is faster; The complication rates are low, since it is a minimally invasive procedure; And brings the possibility of the surgery being done in the outpatient clinic..$^{30}$

\section{Bicipital tenotomy}

Since tendinopathy of the long portion of the biceps is a common cause of pain and discomfort in patients with massive bony ruptures, it makes sense that tenodesy or tenotomy may lead to symptomatic relief. However, since they do not prevent joint degeneration, they are not indicated for patients with repairable ruptures and high functional requirements. ${ }^{2,10}$ There is concern that this procedure may lead to superior humeral head migration and pseudoparalysis. However, retrospective studies have shown that there is no evidence of this superior migration and that it is undisputed that bicipital tenotomy does not provoke pseudoparalysis, and is associated until the improvement of function, most probably due to the relief of pain. ${ }^{9,10}$

The results have been promising. Boileau et al reviewed 68 patients submitted to bicipital tenotomy or tenodesis and, after 3 years, $78 \%$ were satisfied and all recovered active elevation. ${ }^{9}$ Walch et al. ${ }^{52}$ studied the results of 307 arthroscopic bicycling tenotomies performed on patients with irreparable massive ruptures or who were unwilling to cooperate in the rehabilitation required after coifera repair surgery. After 57 months, the mean Constant score increased from 48 points to 68 and the satisfaction rate reached $87 \% .^{2,10}$

\section{Deltoid flap}

The deltoid flap was first described in 1978 by Takaishi and reviewed in 1985 by the French surgeons Apoil and Augereau. ${ }^{32}$ Its main disadvantage is the compromise of deltoid muscle integrity. ${ }^{33}$ The conclusions regarding the usefulness of this procedure are quite different. Schneeberger concluded that the modified deltoid flap is a viable alternative for the treatment of irreparable coifa ruptures in young patients, since of the 57 patients $91 \%$ showed pain relief. ${ }^{33}$ Glanzmann has not found any advantage of this invasive technique in the face of arthroscopic debridement, which does not alter the integrity of the deltoid. He found, after reconstruction of 31 massive ruptures, that the survival rate of deltoid flap was less than $20 \%$. Both Glanzmann and $\mathrm{Lu}$ state that this procedure does not prevent superior migration and osteoarthritic changes. ${ }^{32,34}$

\section{Glenohumeral arthrodesis}

Glenohumeral arthrodesis is a difficult procedure and poorly tolerated by patients. At present, there are few indications for arthrodesis of massive coil ruptures, being reserved for pain relief in patients undergoing multiple surgeries without success, with a history of infection or an inefficient deltoid. ${ }^{2,20}$

\section{Complete repair}

Good to excellent results, significant improvement in quality of life, satisfaction rates of around $94 \%$, and deceleration of joint degeneration have established this technique as the gold standard for the treatment of massive coffin ruptures.$^{35}$ Even so, Bjurkenheim et al reported that the results of massive rupture repairs were markedly lower than those of the smaller repair ruptures. ${ }^{2}$ The possibility of cure with complete repair is related to the size of the rupture, the acromiomeral distance, the degree of muscle atrophy, the amount of adipose infiltration, and also the time that elapses between the rupture and the procedure. Repaired as soon as possible..$^{10,36}$

One of the most important points in the repair is the mobilization of the retracted tendon to its place of insertion in the great tuberosity. Therefore, it is essential that the subacromial and subdeltoid adhesions are removed and that the bursal tissue is excised for better visualization of the rupture pattern. Lo and Burkhart report that $90 \%$ of 94 massive ruptures could be repaired primarily to the bone after adequate adhesion lysis using the margin convergence technique., ${ }^{2,9}$

Opinions differ as to which technique should be used for complete repair. The double row repair has been defended by some authors, claiming to have better biomechanical characteristics, greater bonetendon contact and lower rate of recurrence compared to single row repair. ${ }^{2}$ Park J Y et al. ${ }^{37}$ showed that the ASES and Constant scores after double row repairs were significantly better than after single row repair. Papadopoulos et al. ${ }^{35}$ found that double-row sutures had higher tendon healing rates. Other authors claim that the use of double row may result in an exaggerated tension of the hood. For this same reason, Snyder et al defend a "medial" repair with a single row of sutures in the joint margin. ${ }^{2}$ Regarding the comparison of the arthroscopic vs. open approach, there is no strong evidence that one has better results than the other, although the arthroscopic route becomes increasingly popular. ${ }^{10,38}$ Beauchamp et al. ${ }^{39}$ studied the advantages and disadvantages of using local anesthesia with sedation instead of general anesthesia. The study demonstrated that local anesthesia with sedation allows sufficient pain control, in addition to enabling an in vivo test of the robustness of the repair. It also gives the opportunity to be operated on patients who otherwise would not be: patients with a high anesthetic risk or with contraindications for locoregional anesthesia.

As previously mentioned, when it is possible to perform it, complete repairing results in very favorable results. Lam and Mok reviewed 74 patients aged 65 years or older undergoing massive symptomatic rupture repair. Two years later, $84 \%$ of patients were satisfied and $93 \%$ achieved pain relief. ${ }^{2}$ Zumstein et al. ${ }^{8}$ followed 27 patients undergoing open transosseous repair. After 3.1 years, all patients showed good to excellent results and 22 patients remained satisfied with the result after 9.9 years. However, there was a recurrence rate of $57 \%$.

Despite excellent results, complete repair is not without complications. The most common complications of open repair are deltoid detachment, a new rupture and infection. ${ }^{40}$ Deltoid detachment usually occurs 6 weeks after surgery in the active shoulder rehabilitation period. It causes decreased strength and deformity, but also decreased pain. In a study with 112 patients with massive open- 
wound repair treated with open repair, 9 patients $(8 \%)$ with of the deltoid. Gumina et al recommend for the prevention of thicker and U-shaped sutures. ${ }^{40}$

Regarding the existence of a new rupture, it was observed that most occur early in the postoperative period and that the initial rupture size and the age of the patient influence their incidence..$^{35,41}$ Jost et al. ${ }^{2}$ also found a relationship between the extent of fat infiltration of the infra- and supraspinatus muscles and the occurrence of new rupture. ${ }^{2}$ Reinforcement techniques were identified to reduce the likelihood of rupture recurrence: stronger sutures; other suture configurations (eg, Mason-Allen technique); Anchors of wider and more rigid sutures. ${ }^{35}$

\section{Partial Repair}

When complete repair is not possible because of the extent of the rupture, the retraction or poor quality of the tissue, partial repair can also lead to improved pain and functional capabilities, achieving high satisfaction rates., ${ }^{9,15,42}$ Duralde \& Bair $^{2}$ studied 24 patients who underwent open partial repair, since complete repair was not possible. 43 months after surgery, $67 \%$ of the patients had excellent results and $92 \%$ were satisfied with the result. Burkhart et al. ${ }^{2}$ obtained similar results in 14 patients. Berth et al. ${ }^{30}$ also concluded that patients undergoing partial arthroscopic repair have a marked improvement in functional abilities and a more marked recovery in day-to-day activities than patients who underwent only arthroscopic debridement. ${ }^{30}$

\section{Tissue grafts}

They are used when there is tissue deficiency in order to achieve a tensionless repair. They provide mechanical support and have biological properties that favor cell proliferation and differentiation. They can be divided into two major groups: synthetic and biological. Biologicals may further be subdivided into autologous (long portion of the biceps) or allografts (derived from the dermis or submucosa of the small intestine).$^{2,43,44}$ Discontinuation or moderation of the use of synthetic and submucosal grafts has been recommended because of the risk of inflammatory response and foreign body reaction..$^{2,10,44,45}$

\section{Dermis graft}

The repair with the use of human dermis allograft is a technique that leads to significant improvement of pain, range of motion and strength. Gupta et al studied 24 patients with good active range of motion, absence of high grade adipose infiltration or glenohumeral arthrosis, and found a $100 \%$ satisfaction rate. Postoperative ultrasound after 3 years demonstrated completely intact repairs in most patients. Do not infection or tissue rejection occurred. The study suggests that this allograft has the capacity to behave as a native tendon both biomechanically and histologically. ${ }^{23}$ Bond et al ${ }^{46,47}$ studied 16 patients undergoing arthroscopic repair with dermis grafts and 15 of these patients were satisfied with the result, with total graft incorporation in 13 of them. Burkhead et al. ${ }^{2}$ examined 17 patients and, 1.2 years after surgery, $24 \%$ showed some degree of recurrence. ${ }^{2}$

\section{Graft of long portion of bícipite}

Being an autograft, this method has a lower risk of inflammation and foreign body reaction. Sano et $a .^{43}$ obtained a reconstruction success rate of $92.9 \%$, considering this option as one of the best for irreparable massive ruptures.

\section{Tendon transfer}

The size of the rupture and the irreversible degeneration and retraction of musculotendinous units caused by it, causes that in
$30 \%$ of the Large dorsal transfer. The transfer of large dorsal mass to the treatment of the massive bonnet rupture was initially proposed by Gerber et al. (Figure 3). ${ }^{2,48,49}$ It is more used in posterior superior ruptures with consequent decompensated external rotation and abduction weakness. ${ }^{11,50}$ Some authors argue that this technique is also a valid option for pseudoparalysis of external rotation..$^{10}$ In order for the transfer to reestablish the balance of the coronal and transverse forces, the subscapular tendon and the deltoid muscle must be intact, which is a prerequisite for this surgery. ${ }^{27,49}$

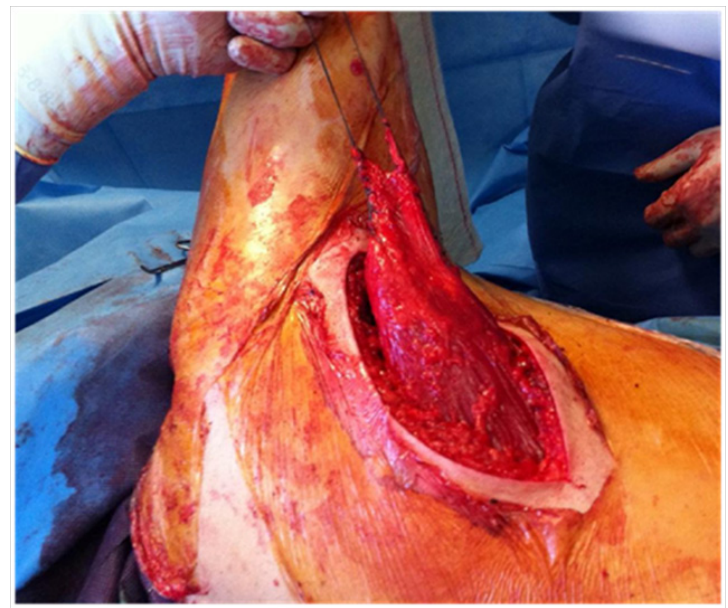

Figure 3 Mobilization of the dorsal large muscle for its transfer.

Weening et al. ${ }^{27}$ followed 16 patients undergoing this transfer for treatment of irreparable ruptures associated with chronic pain and functional impairment of the 16 patients, only 1 showed no improvement in pain and functional capacity. However, activities like washing the head and hanging clothes remained difficult. This difficulty can be justified by the inability of the large dorsal to center the humeral head on the joint as it is done by the hood muscles. In their study, Zafra et al. ${ }^{48}$ reported an improvement in pain in $88 \%$ of patients.

Miniaci \& MacLeod ${ }^{2}$ reported a satisfaction rate of $83 \%$, Warner and Parsons of $73 \%$ and Iannotti et $a . .^{25}$ of $64 \%$. On average the transfer of the dorsal one cause a gain of $35^{\circ}$ in the previous active elevation, a gain of $10^{\circ}$ in the active external rotation and a $70 \%$ increase in the abduction force. However, a return to normal range and force should not be expected. It is still not possible to say whether the concomitant transfer of the greater round influences the results. ${ }^{11}$

This procedure had a low number of complications, reaching $9.5 \%$ according to Namdari et al. ${ }^{11,27}$ However, it was detected that in more than $50 \%$ of the shoulders submitted to the transfer of the large dorsal one there was an increase of the superior migration. ${ }^{11}$ Gumina et al. ${ }^{40}$ described the detachment of the deltoid as one of the most common complications.

Transfer of the large breastplate and the transfer of the large breast is more commonly used in anterior superior ruptures, since it is indicated for irreparable subscapular ruptures. ${ }^{2,9,10}$ Jost et al reported satisfactory results in 24 of 30 patients, while Wirth and Rockwood reported the same in 10 of 13 . Resch et al obtained good to excellent results in 9 of 12 patients.

\section{Hemiarthroplasty}

Hemiarthroplasty has become the standard surgical procedure for cochlear arthropathy despite mixed results. It is indicated for the treatment of massive ruptures associated with glenohumeral and / or subacromial osteoarthrosis with intact deltoid muscle..$^{10,20}$ 
The results are controversial. The largest series of patients with cochlear arthropathy submitted to hemiarthroplasty was reviewed by Sanchez-Sotelo et al. ${ }^{20}$ we reviewed 33 shoulders of 30 patients with a follow-up of 5 years. Good results were achieved in $67 \%$ of patients. The mean pain score decreased from 4.2 to 2.2. However, 9 patients maintained moderate pain, 8 shoulders suffered progressive progressive erosion of the glenoid, 14 erosion of the acromion and 2 patients suffered an acromial fracture. ${ }^{20}$ Field et al reviewed the results of hemiarthroplasty of 16 patients with cochlear arthropathy, 63\% obtained satisfactory results. Williams and Rockwood reported the results of 21 hemiarthroplasties and, although $86 \%$ had satisfactory results, only 12 patients were painless. ${ }^{2}$

There is a strong concern that hemiarthroplasty will lead to progressive bone loss. This progressive glenoid and acromial erosion has been proposed as an explanation for the poor results and the permanence of postoperative pain. Procedures prior to hemiarthroplasty have also been identified as responsible for the failure of the procedure. ${ }^{2,20}$

\section{Total arthroplasty}

Despite the clinical success in the treatment of osteonecrosis, the results in the treatment of hood rupture arthropathy have not been so good. ${ }^{20}$

\section{Reverse arthroplasty}

Reverse arthroplasty restores the surface of the glenohumeral joint, treating arthrosis $;{ }^{19}$ Blocks the superior migration of the humeral head and transforms the movement of the deltoid into rotational movement, maintaining joint stability. ${ }^{1}$ The literature points to the irreparable rupture of the coifa as being the most suitable indication for reverse arthroplasty, as well as argues that reverse arthroplasty Is the most effective treatment of irreversible rupture with pseudoparalysis of anterior elevation. ${ }^{10} \mathrm{An}$ increasing number of publications support the effectiveness of reverse arthroplasty in the treatment of coifera rupture arthropathy, ${ }^{20}$ which is the most common indication of this procedure. ${ }^{19,51}$ It is still a viable option for patients with pain and dysfunction who are not effectively treated with conventional arthroplasty. ${ }^{51}$ Reverse arthroplasty is unable to correct rotation pseudoparalysis external. Thus, when we are confronted with a combined pseudoparalisis of anterior and external rotation, the combination of the reverse arthroplasty with the transfer of the large dorsal is advised. ${ }^{10}$

Unlike other procedures, an intact coracoacromial ligament is not a prerequisite. The first major contraindication of this technique is, logically, the absence of a functional deltoid, since a normal deltoid function is required for the recovery of active elevation after reverse arthroplasty. ${ }^{1,19,20}$ Non-existence of stock of adequate glenoid bone, previous shoulder infections and significant medical comorbidities. ${ }^{20}$

The short-term results have been encouraging, but the long-term results are still under study. The available literature shows a prosthetic survival rate of $91 \%$ at 120 months. ${ }^{10,52}$ Feeley $^{20}$ concludes that, after reverse arthroplasty, active elevation is considerably improved, although improvements in external rotation are variable. It also states that pain is reduced to minimal or even absent in $81 \%$ to $96 \%$ of patients. Gerber ${ }^{10}$ also states that this procedure is responsible for the drastic improvement of pain in patients with irreparable massive ruptures. He adds that he has had very satisfactory results in the treatment of patients previously submitted to failed repairs. Mulieri et al. ${ }^{51}$ studied 72 shoulders submitted to reverse arthroplasty for treatment of massive rupture of the rotator cuff without glenohumeral arthrosis. $95 \%$ of the patients were satisfied with the result, showing improvement in ASES, SST and SF-36 scores, as well as improved range of motion. Boileau et al. ${ }^{53}$ studied the results of the reverse arthroplasty in 46 patients, $61 \%$ of whom presented glenohumeral arthrosis. There was no difference in improvement, pain scores and range of motion comparing patients with arthrosis and no arthrosis.

Despite the clinical success of this op surgical option, its use is limited by the high rate of complications. Mulieri \& Wall ${ }^{51}$ reported a complication rate of $19-20 \%$. According to a review of 186 patients, the most common complications are displacement $(7.5 \%)$ and infection (4\%). Less frequently, glenoid fractures, umeral fractures, radial nerve palsy, and loosening of the glenoesphere occur. ${ }^{2}$ Werner et al. studied 58 patients who underwent reverse arthroplasty and found that the overall complication rate was $50 \%$ and that $33 \%$ Of patients required prosthetic revision. ${ }^{2,20}$ They emphasized the importance of the risk of hematoma and postoperative infection due to the dead space surrounding the prosthesis. ${ }^{2}$ Sirveaux et al. ${ }^{20}$ reported a complication rate of $15 \%$ and Frankle et al. ${ }^{1}$ of $21.7 \%$. The risk of complications is more than double in revision surgery than in primary surgery. ${ }^{2,19}$ Previous surgery is a risk factor for complications, need for new surgery and rate of reduced prosthetic survival. Both Werner and Cuff performed better when arthroplasty. Reversal was done as a first option compared to when it was used after repair or failed arthroplasty. ${ }^{1,54}$

\section{Other treatments}

\section{Cell biological therapies}

The rotator cuff rupture cures with a layer of scar tissue that makes repair more likely to fail. Cellular biological therapies have the potential to improve this healing process, and studies with cytokines and transcription factors, such as scleraxis, are being developed with the aim of creating a therapy that improves the repair of ruptures and decreases the rate of failure. ${ }^{7,55}$

\section{Conclusion}

The Rotating Hood Massive Ruture presents itself as a complex orthopedic challenge and there are several therapeutic options available. Conservative treatment achieved good results in many patients, many of them being asymptomatic and having a satisfactory function, through compensatory mechanisms for the potentiation of accessory muscle groups of the hood. Arthroscopic debridement, subacromial decompression and bicycle tenotomy may be indicated in elderly patients with low functional requirements and whose main complaint is pain. Complete repair should be attempted whenever possible, especially in young, symptomatic patients with high functional requirements. The double-row technique is biomechanically more favorable and has a lower recurrence rate. The transfer of tendons such as the large dorsum may be an option for younger patients, in whom repair is not possible. Regarding prosthetic replacement, both hemiarthroplasty and reverse arthroplasty may be indicated in the massive rupture and cochlear arthropathy. Reverse arthroplasty is the most effective treatment, especially when there is pseudoparalysis, even presenting a not insignificant rate of complications.

\section{Conflicts of interest}

None.

\section{Acknowledgements}

None. 


\section{References}

1. Harreld KL, Puskas BL, Frankle M. Massive rotator cuff tears without arthropathy: when to consider reverse shoulder arthroplasty. The Journal of bone and joint surgery. 2011;93(10):973-984.

2. Bedi A, Dines J, Warren RF, et al. Massive tears of the rotator cuff. $J$ Bone Joint Surg Am. 2010;92(9):1894-1908.

3. Rousseau T, Roussignol X, Bertiaux S, et al. Arthroscopic repair of large and massive rotator cuff tears using the side-to-side suture technique. Mid-term clinical and anatomic evaluation. Orthop Traumatol Surg Res. 2012;98(4 Suppl):S1-S8.

4. Laron D, Samagh SP, Liu X, et al. Muscle degeneration in rotator cuff tears. J Shoulder Elbow Surg. 2012;21(2):164-174.

5. Kang JR, Gupta R. Mechanisms of fatty degeneration in massive rotator cuff tears. J Shoulder Elbow Surg. 2012;21(2):175-180.

6. Hawkes DH, Alizadehkhaiyat O, Kemp GJ, et al. Shoulder muscle activation and coordination in patients with a massive rotator cuff tear: an electromyographic study. J Orthop Res. 2012;30(7):1140-1146.

7. Bedi A, Maak T, Walsh C, et al. Cytokines in rotator cuff degeneration and repair. J Shoulder Elbow Surg. 2012;21(2):218-227.

8. Zumstein MA, Jost B, Hempel J, et al. The clinical and structural longterm results of open repair of massive tears of the rotator cuff. $J$ Bone Joint Surg Am. 2008;90(11):2423-2431.

9. Neri BR, Chan KW, Kwon YW. Management of massive and irreparable rotator cuff tears. J Shoulder Elbow Surg. 2009;18(5):808-818.

10. Gerber C, Wirth SH, Farshad M. Treatment options for massive rotator cuff tears. Journal of shoulder and elbow surgery. 2011;20(2 Suppl):S20-S29.

11. Namdari S, Voleti P, Baldwin K, et al. Latissimus dorsi tendon transfer for irreparable rotator cuff tears: a systematic review. J Bone Joint Surg Am. 2012;94(10):891-898.

12. Loew M, Raiss P. A symptom-based classification for shoulders with massive rotator cuff defects. Int orthop. 2010;34(1):63-69.

13. Steenbrink F, de Groot JH, Veeger HE, et al. Glenohumeral stability in simulated rotator cuff tears. Journal of biomechanics. 2009;42(11):1740-1745.

14. Tetreault P, Levasseur A, Lin JC, et al. Passive contribution of the rotator cuff to abduction and joint stability. Surgical and radiologic anatomy. 2011;33(9):767-773.

15. Favard L, Berhouet J, Colmar M, et al. Massive rotator cuff tears in patients younger than 65 years. What treatment options are available? Orthopaedics \& traumatology, surgery \& research. 2009;95(4 Suppl 1):S19-S26.

16. Hamada K, Yamanaka K, Uchiyama Y, et al. A radiographic classification of massive rotator cuff tear arthritis. Clin Orthop Relat Res. 469(9):2452-2460.

17. Kim JR, Cho YS, Ryu KJ, et al. Clinical and radiographic outcomes after arthroscopic repair of massive rotator cuff tears using a suture bridge technique: assessment of repair integrity on magnetic resonance imaging. Am J Sports Med. 2012;40(4):786-793.

18. Drake GN, O'Connor DP, Edwards TB. Indications for reverse total shoulder arthroplasty in rotator cuff disease. Clinical orthopaedics and related research. 2010;468(6):1526-1533.

19. Nam D, Maak TG, Raphael BS, et al. Rotator cuff tear arthropathy: evaluation, diagnosis, and treatment: AAOS exhibit selection. $J$ Bone Joint Surg Am. 2012;94(6):e34.

20. Feeley BT, Gallo RA, Craig EV. Cuff tear arthropathy: current trends in diagnosis and surgical management. J Shoulder Elbow Surg. 2009;18(3):484-494.
21. Boykin RE, Friedman DJ, Zimmer ZR, et al. Suprascapular neuropathy in a shoulder referral practice. J Shoulder Elbow Surg. 2011;20(6):983-938.

22. Berhouet J, Collin P, Benkalfate T, et al. Massive rotator cuff tears in patients younger than 65 years. Epidemiology and characteristics. Orthopaedics \& traumatology, surgery \& research. 2009;95(4 Suppl 1):S13-S18.

23. Gupta AK, Hug K, Berkoff DJ, et al. Dermal tissue allograft for the repair of massive irreparable rotator cuff tears. Am J Sports Med. 2012;40(1):141-147.

24. Derwin KA, Badylak SF, Steinmann SP, et al. Extracellular matrix scaffold devices for rotator cuff repair. J Shoulder Elbow Surg. 2010;19(3):467-476.

25. Petersen SA, Murphy TP. The timing of rotator cuff repair for the restoration of function. J Shoulder Elbow Surg. 2011;20(1):62-68.

26. Nho SJ, Delos D, Yadav H, et al. Biomechanical and biologic augmentation for the treatment of massive rotator cuff tears. Am J Sports Med. 2010;38(3):619-629.

27. Weening AA, Willems WJ. Latissimus dorsi transfer for treatment of irreparable rotator cuff tears. Int Orthop. 2010;34(8):1239-1244.

28. Zingg PO, Jost B, Sukthankar A, et al. Clinical and structural outcomes of nonoperative management of massive rotator cuff tears. J Bone Joint Surg Am. 2007;89(9):1928-1934.

29. Levy O, Mullett H, Roberts S, et al. The role of anterior deltoid reeducation in patients with massive irreparable degenerative rotator cuff tears. J Shoulder Elbow Surg. 2008;17(6):863-870.

30. Berth A, Neumann W, Awiszus F, et al. Massive rotator cuff tears: functional outcome after debridement or arthroscopic partial repair. $J$ Orthop Traumatol. 2010;11(1):13-20.

31. Liem D, Lengers N, Dedy N, et al. Arthroscopic debridement of massive irreparable rotator cuff tears. Arthroscopy. 2008;24(7):743-748.

32. Lu XW, Verborgt O, Gazielly DF. Long-term outcomes after deltoid muscular flap transfer for irreparable rotator cuff tears. J Shoulder Elbow Surg. 2008;17(5):732-737.

33. Schneeberger AG, Schuler L, Rikli D, Thur C (2012) Rotator cuff tears treated with a modified deltoid flap repair technique. J Shoulder Elbow Surg. 2008;21(3):310-318.

34. Glanzmann MC, Goldhahn J, Flury M, et al. Deltoid flap reconstruction for massive rotator cuff tears: mid- and long-term functional and structural results. J Shoulder Elbow Surg. 2010;19(3):439-45.

35. Papadopoulos P, Karataglis D, Boutsiadis A, et al. Functional outcome and structural integrity following mini-open repair of large and massive rotator cuff tears: a 3-5 year follow-up study. J Shoulder Elbow Surg. 2011;20(1):131-137.

36. Yamaguchi $H$, Suenaga $N$, Oizumi $N$, et al. Open repair for massive rotator cuff tear with a modified transosseous-equivalent procedure: preliminary results at short-term follow-up. J Orthop Sci. 2011;16(4):398-404.

37. Park JY, Lhee SH, Choi JH, et al. Comparison of the clinical outcomes of single-and double-row repairs in rotator cuff tears. The American journal of sports medicine. 2008;36(7):1310-1316.

38. Cho $\mathrm{CH}$, Song KS, Min BW, et al. Anterolateral approach for mini-open rotator cuff repair. Int Orthop. 2012;36(1):95-100.

39. Beauchamp M, Roy JD. Arthroscopic repair of large and massive rotator cuff tears performed under local anaesthesia and sedation. J Shoulder Elbow Surg. 2009;18(5):e18-e20.

40. Gumina S, Di Giorgio G, Perugia D, et al. Deltoid detachment consequent to open surgical repair of massive rotator cuff tears. Int Orthop. 2008;32(1):81-84. 
41. Miller BS, Downie BK, Kohen RB, et al. When do rotator cuff repairs fail? Serial ultrasound examination after arthroscopic repair of large and massive rotator cuff tears. Am J sports med. 2011;39(10):2064-2070.

42. Iagulli ND, Field LD, Hobgood ER, et al. Comparison of partial versus complete arthroscopic repair of massive rotator cuff tears. Am J Sports Med. 2012;40(5):1022-1026.

43. Sano H, Mineta M, Kita A, et al. Tendon patch grafting using the long head of the biceps for irreparable massive rotator cuff tears. Journal of Orthopaedic Science. 2010;15(3):310-316.

44. Rotini R, Marinelli A, Guerra E, et al. Human dermal matrix scaffold augmentation for large and massive rotator cuff repairs: preliminary clinical and MRI results at 1-year follow-up. Musculoskelet surg. 2011;95Supp11:S13-S23.

45. Longo UG, Lamberti A, Khan WS, et al. Synthetic augmentation for massive rotator cuff tears. Sports medicine and arthroscopy review. 2011;19(4):360-365.

46. Snyder SJ, Arnoczky SP, Bond JL, et al. Histologic evaluation of a biopsy specimen obtained 3 months after rotator cuff augmentation with GraftJacket Matrix. Arthroscopy: the journal of arthroscopic \& related surgery : official publication of the Arthroscopy Association of North America and the International Arthroscopy Association. 2008;25(3):329-333.

47. Bond JL, Dopirak RM, Higgins J, et al. Arthroscopic replacement of massive, irreparable rotator cuff tears using a GraftJacket allograft: technique and preliminary results. Arthroscopy. 2008;24(4):403-409e1.
48. Zafra M, Carpintero P, Carrasco C. Latissimus dorsi transfer for the treatment of massive tears of the rotator cuff. Int Orthop. 2009;33(2):457-462.

49. Lehmann LJ, Mauerman E, Strube T, et al. Modified minimally invasive latissimus dorsi transfer in the treatment of massive rotator cuff tears: a two-year follow-up of 26 consecutive patients. Int Orthop. 2009;34(3):377-383.

50. Morelli M, Nagamori J, Gilbart M, et al. Latissimus dorsi tendon transfer for massive irreparable cuff tears: an anatomic study. Journal of shoulder and elbow surgery. 2008;17(1):139-143.

51. Mulieri P, Dunning P, Klein S, et al. Reverse shoulder arthroplasty for the treatment of irreparable rotator cuff tear without glenohumeral arthritis. J Bone Joint Surg Am. 2010;92(15):2544-2556.

52. Walch G, Boileau P, Noel E. Shoulder arthroplasty: evolving techniques and indications. Joint Bone Spine. 2010;77(6):501-505.

53. Boileau P, Gonzalez JF, Chuinard C, et al. Reverse total shoulder arthroplasty after failed rotator cuff surgery. J Shoulder Elbow Surg. 2009;18(4):600-606.

54. Cuff D, Pupello D, Virani N, et al. Reverse shoulder arthroplasty for the treatment of rotator cuff deficiency. J Bone Joint Surg Am. 2008;90(6):1244-1251.

55. Gulotta LV, Rodeo SA. Emerging ideas: Evaluation of stem cells genetically modified with scleraxis to improve rotator cuff healing. Clin Orthop Relat Res. 2011;469(10):2977-2980. 